\title{
Friction Characteristics Of Surface Modification 304 Steel Under Wind Lubrication
}

\author{
Chen Wengang ${ }^{\mathrm{a}}$, Liu Xueyuan ${ }^{\mathrm{b}}$ and Zhen Lili ${ }^{\mathrm{c}}$ \\ College of Mechanics Engineering \& Transportation Southwest Forestry University, Kunming \\ 650224,China \\ Achenwengang999@163.com, “corresponding author, b690850094@qq.com, "28465623@qq.com
}

Keywords: 304 steel, Gas nitriding, Stripe texture, Wind lubrication

\begin{abstract}
A stripe texture with diameter and spacing of $300 \mu \mathrm{m}$ was prepared on the surface of 304 steel substrate via M-DPSS-50 semiconductor laser marking machine. Then, nitriding treatment on the textured surface was conducted by using well type gas nitriding furnace. The chemical composition, surface morphology and surface micro-hardness were measured by $\mathrm{X}$ ray diffraction, optical microscope and surface micro-hardness tester. The friction and wear properties of the composite modification surface under dry friction and wind lubricated friction conditions were detected by MRTR computer controlled friction and wear testing machine. The results show that an regular textured surface was obtained. The surface microhardness of the gas nitriding treated sample reached $444.65 \mathrm{HV} 0.1$, which significantly higher than the 304 stainless steel substrate surface of 222.58HV0.1. The modified surface has excellent anti-friction and anti-wear effect under the condition of wind lubrication.
\end{abstract}

\section{Introduction}

304 stainless steel is a widely used nickel chromium stainless steel with substrate for FCC Fe austenitic. the austenitic stainless steel has excellent corrosion resistance, good heat resistance, low temperature strength and mechanical properties, but it usually has low hardness, friction and poor wear performance. So it can not meet the composite performance requirements of both wear resistance and corrosion resistance in many cases ${ }^{[1]}$. Generally it cannot be used to make a pair of friction components. In a limited application, the drive shaft or engagement with stainless steel as raw materials in the work process frequently occurs viscous or occlusion phenomenon because of the low surface hardness and strength ${ }^{[2]}$. Therefore, the tribological properties enhancement of 304 stainless steel surface and the application range prolongation has very important significance.

The traditional tribology theory consider that the more smooth contact surface cause the more small force of friction. But in recent years a large number of micro modeling on the friction surface research have been demonstrated which can effectively improve the surface tribological properties, and extensive attention has been paid to ${ }^{[3-6]}$. Previous studies have found that the surface texture can play the effect of friction reduction in almost all of the friction conditions ${ }^{[7-8]}$. In recent years, the research of laser processing on the surface of the material has been favored by the majority of researchers. The regular texture can be prepared on the surface of the material by using this method. And in the field of material surface chemical modification, surface nitriding is a good choice. there are three kinds of typical technology can achieve this kind of modified layer: gas nitriding, plasma nitriding and nitrogen ion injection process ${ }^{[9-12]}$. Gas nitriding with ammonia or nitrogen/hydrogen mixture as the nitriding media, through the physical and chemical interaction with the work piece surface to make the active nitrogen atoms through the surface into the austenitic stainless steel substrate. Gas nitriding process is relatively mature, equipment requirements are not high, the project cost is relatively cheap. Well type gas nitriding furnace is mainly used for gas nitriding of carbon steel parts, mold quenching and other heat treatment. The equipment is provided with a liquid dropping device, can also be carried out in gas nitrocarburizing (soft nitriding treatment). 
The friction coefficient of objects move in the atmosphere is $0.1 \sim 0.8$, Contrast to the friction coefficient in vacuum will be more than 1 , which indicates that the gas can be used as lubricant ${ }^{[13-14]}$. Gas Static pressure lubrication and dynamic pressure lubrication has been applied in the friction reduction. The United States, Germany and Japan have reported the application of gas film technology and obtained a more excellent effect respectively ${ }^{[15-16]}$.

According to this, this study used laser processing and well type gas nitriding technique to modify the surface of 304 steel. Then, the anti-friction and anti-wear properties of the composite modification surface was tested under the wind lubrication condition. This study has a great significance to the expansion of the application of 304 steel.

\section{Experimental Materials And Processes}

Experimental Materials And Equipment. The choice of matrix material in this study is 304 stainless steel plate. The experimental equipment and testing instruments used in the study include: M-DPSS-50 semiconductor laser marking machine, well type plasma nitriding furnace, the MH-6 micro-hardness tester, MRTR microcomputer controlled multifunctional friction and wear testing machine, YM200 optical microscope, D/MAX-Ultima+ $\mathrm{X}$ ray diffraction instrument.

Experimental Processes. (1) A stripe texture with diameter and spacing of $300 \mu \mathrm{m}$ was prepared on the surface of 304 steel substrate via M-DPSS-50 semiconductor laser marking machine. The relevant parameters in the preparation: voltage for $15 \mathrm{~V}$, current for $8 \mathrm{~A}$, marking method for filling.

(2) Surface nitriding treatment. The textured surface and 304 steel substrate were nitrided at $580{ }^{\circ} \mathrm{C}$ for $3 \mathrm{~h}$ by using well type gas nitriding furnace. D/MAX-Ultima $+\mathrm{X}$ X-ray diffraction and MH-6 microhardness tester was used to detect the phase composition and surface hardness. The micro-hardness measurement load of $0.98 \mathrm{~N}$, loading duration is $20 \mathrm{~s}$. In order to improve the measurement accuracy, 6 point measurements of each sample were conducted and then took the average.

(3) The tribological characteristics test. The friction and wear properties of the composite modification surface under dry friction and wind lubricated friction conditions were detected by MRTR computer controlled friction and wear testing machine. Experimental parameters: load for 9N, speed for $100 \mathrm{rpm}$ and friction time for $10 \mathrm{~min}$. Wind lubrication equipment used for this study was Qianyi 15 type AC direct drive blower with rated voltage 6-12V and maximum power $15 \mathrm{~W}$. The wind direction is horizontal to the stripe direction. The relative motion of the upper and lower samples is reciprocating linear motion, the single line length is $5 \mathrm{~mm}$. The friction pair in the test is a A12O3 ceramic rod with a diameter of $24 \mathrm{~mm}$. The friction coefficient was recorded by automatic recording system of MRTR microcomputer controlled multifunctional friction and wear test machine. Data acquisition time interval is 10 s. The wear morphology of the samples was detected by YM200 optical microscope.

\section{Results And Discussion}

Textured Surface Morphology.Fig.1 is the optical microscope morphology of textured surface before and after nitriding. It can be seen from Figure 1(a) that the surface of the laser textured 304 steel is very regular and clear. The width and spacing of the fringes are mostly $300 \mathrm{um}$. Figure $1(\mathrm{~b})$ is the texture surface topography after gas nitriding process. It can be clearly seen from the figure that the surface texture still maintain a clear pattern of texture characteristics and it not destroy the original surface texture, But the performance of the surface color change due to the change of material surface phase. 


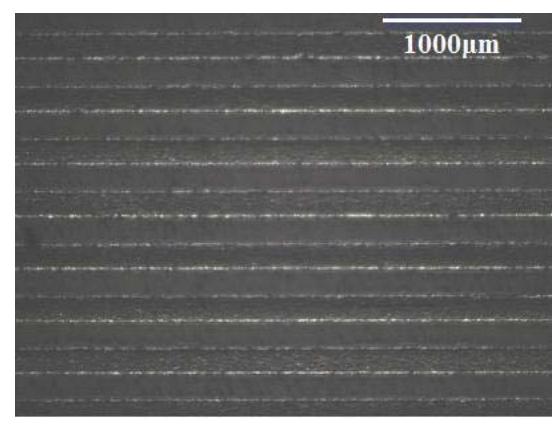

a Before nitriding

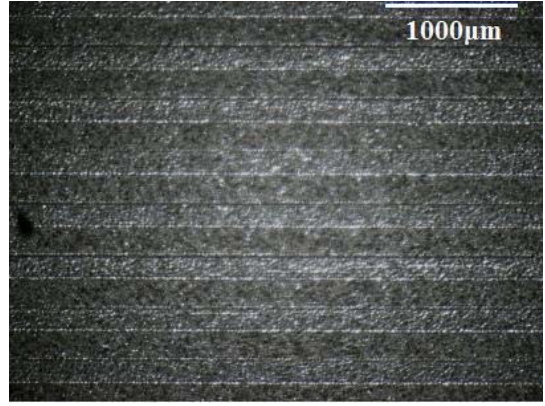

b After nitriding

Fig.1 The morphology of textured surface before and after nitriding

Material Properties Of Gas Nitriding Treatment. Fig. 2 is XRD comparison chart of smooth 304 steel surface before and after gas nitriding. It can be seen from the figure that the original structure of 304 steel is austenitic stainless steel, and the nitriding layer is a single $\gamma \mathrm{N}$ phase after gas nitriding. Table 1 is the comparison $2 \theta$ value table before and after nitriding. It can be seen from the table that all diffraction peaks of $\gamma \mathrm{N}$ phase offset to low angle compared with the diffraction peaks of 304 stainless steel substrate. This is because that the crystal structure of the $\gamma \mathrm{N}$ phase is a face centered cubic structure with a higher deformation layer density and a lower twin layer density, the deformation layer caused by the nitriding makes the $\gamma \mathrm{N}$ phase $\mathrm{X}$ ray diffraction peak shift.

Table 1 The comparison $2 \theta$ value table before and after nitriding

\begin{tabular}{ccccc}
\hline Crystal surface & 111 & 222 & 220 & 311 \\
\hline 304 steel & 43.62 & 50.66 & 74.74 & 90.60 \\
Gas nitriding 304 steel & 43.56 & 50.52 & 74.4 & 90.24 \\
\hline
\end{tabular}

Table 2 is the surface micro hardness Comparison of the sample before and after nitriding. It can be seen from the table that the average microhardness of the 304 steel surface is $222.58 \mathrm{HV} 0.1$. And surface microhardness after gas nitriding reached $444.65 \mathrm{HV} 0.1$. This shows that the microhardness of the surface increases significantly after gas nitriding. This is due to the Fe-Cr-Ni three matrix atoms and interstitial nitrogen atoms which dissolved in the octahedral interstitial atoms form a saturated superhard expanded austenite $\mathrm{N}$ phase. It leading to high hardness, high resistance to fatigue performance and excellent resistance to wear anti corrosion performance.
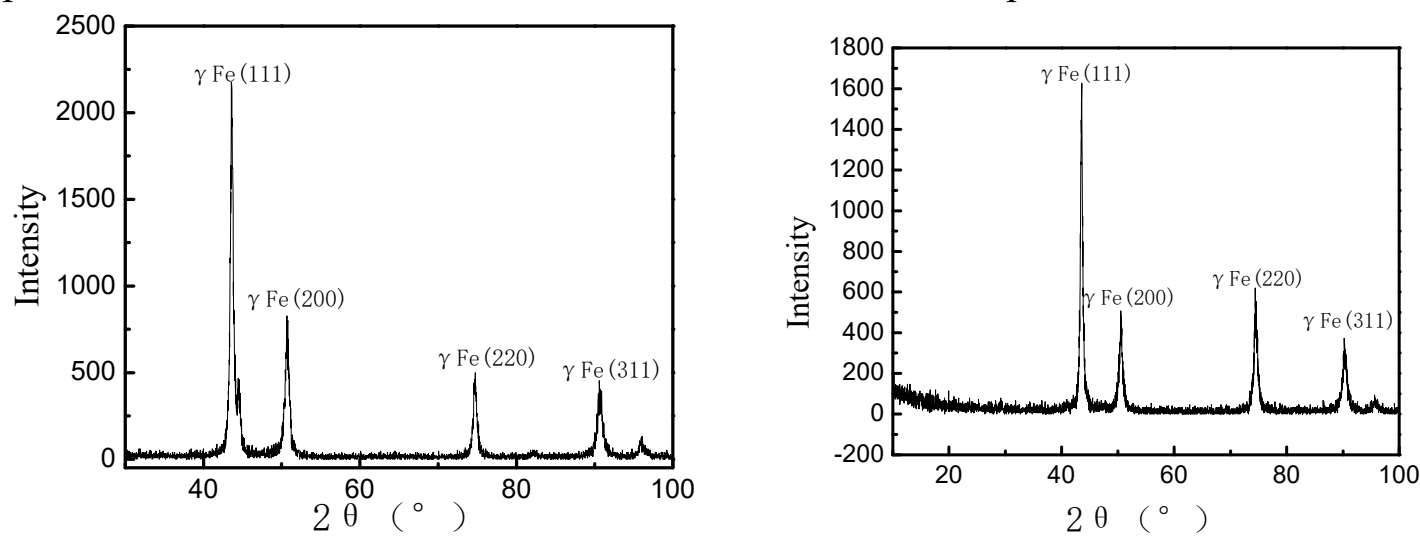

Fig. 2 Comparison of XRD before and after nitriding

Table 2 Surface micro hardness Comparison of the sample before and after nitriding (HV0.1 load $100 \mathrm{~g})$

\begin{tabular}{cccccccc}
\hline Samples & 1 & 2 & 3 & 4 & 5 & 6 & Average \\
\hline 304 Steel & 210.0 & 231.8 & 224.0 & 224.6 & 226.2 & 218.9 & 222.58 \\
Nitriding steel & 454.9 & 482.2 & 427.8 & 433.7 & 429.1 & 440.2 & 444.65 \\
\hline
\end{tabular}

Friction And Wear Characteristics. The contrast curve of friction coefficient under different friction conditions is shown in Figure 3. The average friction coefficient of the friction pair in the two conditions is shown in the Table 3. From Figure 3 can be seen that the friction coefficient of the friction pairs under the dry friction condition is higher than that of the gas lubricated friction pairs, and the phenomenon is more obvious in the early stage of the experiment. The reason of large 
fluctuations in the initial stage can be attributed to that this is the running in phase of the friction pair. The surface matrix wear amount is larger at this stage, which cause the sharp increase of the friction coefficient. Then, the friction pair in the best friction contact state, resulting in friction coefficient tend to be gentle. And under the condition of gas lubrication. The friction coefficient increased more slowly at the initial stage. The friction coefficient increases to high values until the time is $340 \mathrm{~s}$. The reason of friction coefficient of friction increased slowly can be due to the wear debris generated in the friction test can blow away from the friction contact area. The data in Table 2 shows that the average friction coefficient of the gas lubricated friction pairs is significantly lower than that of the friction pairs under dry friction. Figure 4 is the worn surface under different friction conditions. It can be seen from the figure that there a plurality of straight line type scratches appeared on the surface both under the condition of dry friction and in wind lubrication condition. But the quantity and the grinding mark depths of the scratches on the specimen under wind lubrication are less and shallow compared with the dry friction condition. It indicated that gas lubricated indeed played a significant effect of reducing the wear.

The minor friction coefficient and wear mark phenomenon of composite modified surface under wind lubrication condition can be attributed to two reasons. The first one is that the wind can take off the wear debris generated in the process of friction. The second one is that the presence and flow of wind in the micro texture form a dynamic pressure lubrication effect between the specimen and the specimen. that is additional fluid dynamic pressure effect theory ${ }^{[17]}$. Gas lubrication is the use of gas as a lubricant. The physical law applicable to hydrodynamic lubrication can also be applied to gas. Gas lubrication can form a layer of complete gas film to support the load, reduce friction under the effect of hydrodynamic pressure effect, static effect and extrusion effect. Hu's research ${ }^{[18]} \operatorname{confirmed}$ that the stribenck curves showed the surface texture in the fluid film lubrication state, but the untextured surface was produced transition to mixed and boundary lubrication. It indicated that surface micro pit extends the friction dynamic pressure lubrication. In this study, although the anti-friction and anti-wear properties of wind lubrication is much less than that of the lubricating oil because of the low viscosity. The wind lubrication play a good anti friction and wear effect to a certain extent.

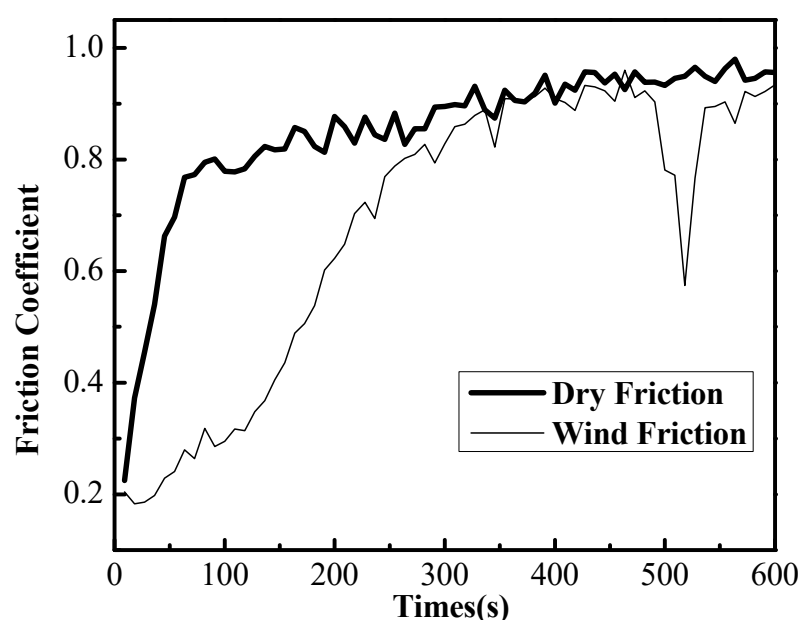

Fig. 3 Comparison of the friction coefficient of different friction pairs under Dry and wind lubrication Table3 Average friction coefficient comparison of friction pairs

\begin{tabular}{ccc}
\hline Conditions & Dry friction & Wind friction \\
\hline Friction coefficient & 0.8533 & 0.6836 \\
\hline
\end{tabular}




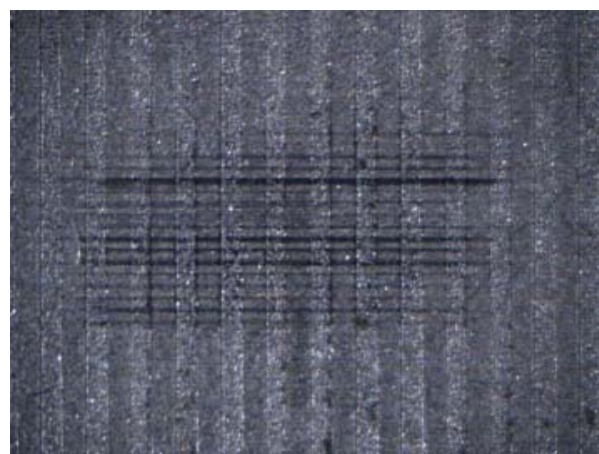

a Dry friction



b Wind friction

Fig.4 The worn surface under different friction conditions

Conclusions.A regular stripe texture was prepared on the surface of 304 steel substrate by laser in this study. Then, nitriding treatment on the textured surface via gas nitriding method. The following results were obtained through the experiment of friction under different conditions:

(1) The average micro-hardness of the 304 steel matrix surface was $222.58 \mathrm{HV} 0.1$, and the micro-hardness of the gas nitriding 304 stainless steel surface increased significantly, which reached 444.65 HV0.1.

(2) The friction and wear properties of the composite modified surface are obviously improved under the condition of wind lubrication. which indicates that the wind has a good lubrication effect. The principle is that the wind can take away the wear debris generated in the friction process from the friction pair contact surface, and the presence and flow of wind in the micro texture form a dynamic pressure lubrication effect between the specimen and the specimen.

\section{Acknowledgement}

This research was financially supported by the "Application of basic research funded projects in Yunnan Province under Grant No. 2010CD067”.

\section{References}

[1] Qiang Tianjun. Tribological properties of Ti and $\mathrm{N}$ ions implanted 304 stainless steel[D]. Chengdu University of Technology, 2011.

[2] Liu Fuchun, Shi Yumin, Han Enhou. Development of surface treatment methods of stainless steel[J]. Journal of Shenyang University of Technology, 2001, 23(1):7-10.

[3] Grabon W, Koszela W, Pawlus P, et al. Improving tribological behaviour of piston ring-cylinder liner frictional pair by liner surface texturing[J]. Tribology International, 2013, 61(2): 102-108.

[4] Li Gan, Shen Mingxue, Meng Xiangkai, et al. An experimental study on tribological properties of groove-textured surfaces of 316L stainless steel[J]. Journal of Functional Materials, 2015, 46(2): 02033-02037.

[5] Andriy Kovalchenko, Oyelayo Ajayi, Ali Erdemir, et al. Friction and wear behavior of laser textured surface under lubricated initial point contact[J]. Wear, 2011,271: 1719-1725.

[6] Yang Chao, Liu Xiaojun, Yang Haidong, et al. Effect of the textured surface on the cutting performance of the tool and the friction property for the rake face[J]. Tribology, 2015, 35(2): 228-235.

[7] Huang Wei, Jiang Liang, Zhou Chuanxi, et al. The lubricant retaining effect of micro-dimples on the sliding surface of PDMS[J]. Tribology International, 2012, 52: 87-93. 
[8] Shum P W, Zhou Z F, Li K Y. To increse the hydrophobicity and wear resistance of diamond-like carbon coatings by surface texturing using laser ablation process[J]. Thin Solid Films, 2013,544: 472-476.

[9] Christiansen T L,Somers M A J. Low-temperature gaseous surface hardening of stainless steel: the current status [J]. International Journal of Materials Research, 2009, 100(10): 1361-1377.

[10] Nakajima M, Nakamura Y, Suzuki K, et al. Effect of solution treatment after nitriding on fatigue properties in type 304 stainless steel [J]. International Journal of Fatigue, 2014, 68: 103-110.

[11] Mendes A F, Scheuer C J, Joanidis I L,et al. Low-temperature plasma nitriding of sintered PIM 316L austenitic stainless steel[J]. Materials Research-Ibero-American Journal of Materials, 2014, 17: 100-108.

[12] Femandes B B,Mandl S,Oliveira R M, et al. Mechanical properties of nitrogen-rich surface layers on SS304 treated by plasma immersion ion implantation[J]. Applied Surface Science, 2014, 310: 278-283.

[13] LIU Yanxia, ZHU Yushu, WANG Xianming, et al. Lubrication of Gas Film and Its Application[J]. JIANGXI SCIENCE, 2002 ( 9) : 174- 177.

[14] Wang Yunfei. Gas lubricated theory and design manual of gas bearings[M]. Beijing: China machine press, 1999.

[15] Ekenes J M, Storey K W, Peterson W S, et al. Fiber optics - a new look at AIRSLIPTM casting $[C] / /$ Elw in L. Light Metals. New Orleans, LA: Minerals Metals \& Materials Soc ( TMS), 1990: 933- 943.

[16] Lorenz H, Schneider W. Improvements in plant operation of the AIRSOL VEILTM billet casting system [C] Euel R C. Light Metals. San Diego, CA: Minerals, Metals \& Materials Soc ( TMS), 1991: 889- 893.

[17] Zhang Yuzhou. Review of Research on Surface Texturing for Improving Tribological Performance[J]. Journal of Chengdu University(Natural Science Edition), 2013, 32(1): 64-68.

[18] Hu Tianchang, Ding Qi, Hu Litian. The Effect of Laser Texturing of GCr15 Steel Surfaces on Their Tribological Properties[J]. Tribology, 2011, 31(5): 447-451. 